\title{
Esophageal Perforation: Clinical Patterns and Outcomes from a Patient Cohort of Western Norway
}

\author{
Jon Arne Søreide ${ }^{a, c} \quad$ Andri Konradsson ${ }^{a} \quad$ Oddvar M. Sandvik ${ }^{a} \quad$ Kjell $\varnothing v r e b \varnothing^{b, c}$ \\ Asgaut Viste ${ }^{b, c}$ \\ ${ }^{a}$ Department of Gastroenterologic Surgery, Stavanger University Hospital, Stavanger, ${ }^{b}$ Department of \\ Gastroenterologic Surgery, Haukeland University Hospital, and ' Department of Surgical Science, University of \\ Bergen, Bergen, Norway
}

\section{Key Words}

Esophageal perforation $\cdot$ Incidence $\cdot$ Treatment $\cdot$ Mortality

\begin{abstract}
Background: Esophageal perforation is a rare, often lifethreatening condition, and management remains challenging. Methods: Retrospective review of consecutive patients with esophageal perforation treated at two university hospitals between 2000 and 2010. Pertinent data from hospital records were retrieved for statistical calculations and evaluation of perforation score. Results: Forty-seven patients [47\% female, median age 62 years (range 15-88)] were included. The annual incidence was $4.7 / 1,000,000$. Perforations were spontaneous in 14 patients (30\%), iatrogenic in 25 $(53 \%)$, and caused by trauma and foreign body impaction in 8 patients $(17 \%)$. ASA score $(p=0.004)$, perforation localization ( $p=0.001)$, diagnostic delay $(p=0.002)$, and perforation score $(p<0.001)$ differed significantly between patient groups with different etiology, but not between groups with different outcomes. Early diagnosis ( $\leq 24 \mathrm{~h}$ ) was significantly associated with a low perforation score $(p=0.033)$. A nonoperative approach was employed in 26 patients (55\%) more commonly for proximally localized perforations $(p=$ 0.045). The non-operative group showed lower severe com-
\end{abstract}

plication rates $(p=0.033)$, shorter ICU stays $(p<0.001)$ and durations of mechanical ventilation $(p=0.022)$. The overall 30 -day mortality was $23.4 \%$. Conclusion: Careful clinical evaluation and appropriate, individualized treatment are important. The high mortality may be partly explained by the underlying disease and the complexity of the clinical condition in many patients.

Copyright $\odot 2013$ S. Karger AG, Basel

\section{Introduction}

Management and clinical decision making in patients with suspected esophageal perforation remain a challenge. Esophageal perforation is a potentially life-threatening condition, with reported mortality rates of between 20 and $40 \%$ in historical series from Norway [1] and from elsewhere [2]. Very low annual incidences of between $3-6 / 1,000,000$ were recently published from studies in Iceland [3] and Denmark [4]. Prospective randomized trials with appropriate statistical power are not available due to the rarity of this condition, so the core knowledge is provided from various retrospective institutional [512] or community-based series $[3,4,13]$. Patients with spontaneous perforation of a healthy esophagus (Boerhaave syndrome $[14,15])$ represent a subgroup of par-

\section{KARGER}

E-Mail karger@karger.com

Accessible online at:

www.karger.com/dsu (c) 2013 S. Karger AG, Basel

0253-4886/12/0296-0494\$38.00/0
Prof. Jon Arne Søreide, MD, PhD, FACS

Department of Gastroenterologic Surgery

Stavanger University Hospital

NO-4068 Stavanger (Norway)

E-Mail jon.soreide@ kir.uib.no 
ticular concern [16]. Heterogeneity with regard to study populations, diagnostic work-up, and applied treatments makes comparisons difficult. Due to the lack of consensus and the obviously very limited personal experience that most health care personnel have with this emergency, case management is largely influenced by the surgeon's experience, judgment, and treatment policy, as well as the resources of the responsible department $[17,18]$. The clinical condition presented at admission and the primary clinical evaluation of patients with esophageal perforation may vary extensively, particularly as imaging techniques improve and the diagnostic and therapeutic toolbox expands [19] with the development of endoscopic or percutaneous approaches to diagnose and drain collections that previously had to be treated surgically.

The purpose of this paper was to analyze demographics, diagnosis, and treatment of consecutive patients with esophageal perforation treated at the two referral centers that cover a population of almost $1,000,000$ people of Western Norway. In addition, we wanted to evaluate the feasibility and possible clinical advantages of using the clinical perforation score, as recently introduced by Abbas et al. [5], in our series of patients with esophageal perforations.

\section{Patients and Methods}

The Haukeland University Hospital and the Stavanger University Hospital cover a catchment area of about $1,000,000$ people, and all esophageal perforations from this area are treated at these hospitals. Eligible patients were identified by electronic search for the diagnosis of esophageal perforation among appropriate ICD9 and ICD-10 codes (K22.3, S27.8, T28.1, T28.6) in the hospital databases; additional searches were done by cross-searching among relevant procedure codes. Hospital records, including surgical notes and descriptions from endoscopic procedures and imaging, were reviewed and data was recorded in an electronic database. Information was retrieved regarding demographics and clinical characteristics (ASA score and comorbidity), and whether any esophageal pathology was known prior to the perforation (esophageal pathology, esophageal stricture, achalasia, malignant tumor, or other conditions). We also recorded the etiology of the perforation (spontaneous, iatrogenic, or other), diagnostic and therapeutic aspects of the management, and outcomes. Localization of the perforation was classified as cervical, thoracic, or distal/abdominal (i.e. the gastro-esophageal junction). All available information was used to calculate the estimated time period (in hours) from onset of the first symptoms or signs of a perforation to a confirmed diagnosis.

As suggested by Abbas et al. [5], a perforation severity score (range 0-18) at the time of presentation was calculated based on clinical variables and findings on imaging. Points were given for each variable (table 1$)$.

Esophageal Perforation Management
Table 1. Clinical perforation score according to Abbas et al. [5]

\begin{tabular}{ll}
\hline Variables & Points \\
\hline Age $>75$ years & 1 \\
Tachycardia $(>100 \mathrm{bpm})$ & 1 \\
Leukocytosis $(>10,000 \mathrm{WBC} / \mathrm{ml})$ & 1 \\
Pleural effusions (on chest X-ray, CT or barium & \\
$\quad$ swallow test) & 1 \\
Fever $\left(>38.5^{\circ} \mathrm{C}\right)$ & 2 \\
Non-contained leak (on barium swallow test or CT) & 2 \\
Respiratory compromise (respiratory rate & \\
$\quad>30 /$ min, increasing oxygen requirement, or & 2 \\
$\quad$ neeed for mechanical ventilation) & 2 \\
Presence of cancer & 3 \\
Presence of hypotension at admission & 3 \\
\hline
\end{tabular}

Clinical perforation score adds up, according to variables that apply, to maximal 18 points.

Complications were recorded based on all available information from hospital records, including consecutive daily notes for patients admitted to the ICU, and pertinent information from imaging and endoscopic examinations. As suggested by Dindo et al. [20], complications were categorized and graded for severity as follows: grade I-II complications do not require any intervention; grade IIIa $+\mathrm{b}$ require surgical, endoscopic, or radiological intervention (grade IIIb if general anesthesia is necessary); grade IV are life-threatening complications (IVa applies to a single-organ dysfunction; IVb when multi-organ dysfunction occurs), and grade $\mathrm{V}$ refers to the death of a patient.

\section{Study Ethics}

The study was approved as a quality control assurance study by the institution's review board (ID No. 169), according to general guidelines provided by the Regional Ethics Committee.

\section{Statistics}

SPSS 19.0 for Mac (SPSS Inc., Chicago, Ill., USA) was used for statistical analysis. A non-parametric distribution of data was assumed, and $\chi^{2}$ or Fisher's exact test was used for dichotomous data where appropriate. The Mann-Whitney $U$ test was used for comparisons of continuous data between two groups, and the KruskalWallis test was applied when more than two groups were compared. All tests were two-tailed, and statistical significance was set at a $\mathrm{p}$ value $<0.05$.

\section{Results}

\section{Patients and Clinical Characteristics}

Forty-seven patients (53\% males), with a median age of 62 years (range 15-88), were diagnosed with esophageal perforations between 2000 and 2010. No significant differences were seen between genders with regard to de- 
Table 2. Characteristics and outcomes according to cause of perforation

\begin{tabular}{|c|c|c|c|c|}
\hline Variable & $\begin{array}{l}\text { Spontaneous } \\
\mathrm{n}=14(30 \%)\end{array}$ & $\begin{array}{l}\text { Iatrogenic } \\
\mathrm{n}=25(53 \%)\end{array}$ & $\begin{array}{l}\text { Other }{ }^{1} \\
n=8(17 \%)\end{array}$ & $\mathrm{p}$ value \\
\hline Gender, M:F & $4: 10$ & $11: 14$ & $5: 3$ & 0.231 \\
\hline Median age, years (range) & $63(47-80)$ & $61(15-89)$ & $57(22-81)$ & 0.838 \\
\hline \multicolumn{5}{|l|}{ ASA score } \\
\hline 1 & 0 & $4(16)$ & $2(25)$ & \multirow[t]{4}{*}{0.004} \\
\hline 2 & $2(14)$ & $13(52)$ & $4(50)$ & \\
\hline 3 & $10(72)$ & $8(32)$ & 0 & \\
\hline 4 & $2(14)$ & 0 & $2(25)$ & \\
\hline \multicolumn{5}{|l|}{ Localization } \\
\hline Cervical & 0 & $4(16)$ & $6(74)$ & \multirow[t]{3}{*}{0.001} \\
\hline Thoracic & $7(50)$ & $11(44)$ & $1(13)$ & \\
\hline Distal/GEJ & $7(50)$ & $10(40)$ & $1(13)$ & \\
\hline Median time to diagnosis, $\mathrm{h}$ (range) & $88(4-178)$ & $20(0-200)$ & $42(2-95)$ & 0.002 \\
\hline Clinical perforation score ${ }^{2}$ (range) & $6(2-14)$ & $5(0-9)$ & $5(0-12)$ & $<0.001$ \\
\hline \multicolumn{5}{|l|}{ Clinical perforation score category ${ }^{2}$} \\
\hline$\leq 2$ & $1(7)$ & $7(28)$ & $1(13)$ & \multirow{3}{*}{0.289} \\
\hline $3-5$ & $5(36)$ & $9(36)$ & $5(62)$ & \\
\hline$>5$ & $8(57)$ & $9(36)$ & $2(25)$ & \\
\hline Surgically treated & $6(43)$ & $11(44)$ & $4(50)$ & 0.944 \\
\hline Median ICU stay, days (range) & $1(0-38)$ & $1(0-41)$ & $0(0-10)$ & 0.418 \\
\hline Days on ventilation, median (range) & $0(0-16)$ & $0(0-15)$ & $0(0-8)$ & 0.936 \\
\hline Days of hospitalization, median (range) & $17(5-110)$ & $22(1-58)$ & $14(1-58)$ & 0.815 \\
\hline In-hospital mortality & $7(50)$ & $5(20)$ & $1(13)$ & 0.076 \\
\hline 30-day mortality & $6(43)$ & $4(16)$ & $1(13)$ & 0.119 \\
\hline
\end{tabular}

\footnotetext{
Values are numbers (\%), unless otherwise indicated. GEJ = Gastro-esophageal junction.

${ }^{1}$ Including food impaction $(n=3)$, multi-trauma patients $(n=3)$, and swallowing part of a denture or foreign bodies $(\mathrm{n}=2) .{ }^{2}$ According to Abbas et al. [5].
}

mographics and basic clinical characteristics. One-third of the patients $(36 \%)$ had no known pathology of the esophagus prior to the perforation. A cervical localization of the perforation was encountered in 10 patients $(21 \%)$, thoracic in $19(41 \%)$, and distal in $18(38 \%)$. Malignancy related to the esophagus was reported in 8 patients $(17 \%)$. Of note, a significant trend ( $\mathrm{p}=0.006$ ) for proximal location was found when the cause of perforation was a benign stricture, or when no esophageal pathology was evident prior to the perforation.

More than half of the patients $(\mathrm{n}=24 ; 51 \%)$ were diagnosed with esophageal perforation within the first $24 \mathrm{~h}$ from symptom onset, $62 \%$ were diagnosed within $48 \mathrm{~h}$, and overall $70 \%$ of the patients had perforation confirmed within $72 \mathrm{~h}$. The remaining 13 patients were diagnosed between 95 and $200 \mathrm{~h}$ from symptom onset. Demographics and outcomes did not differ significantly between those diagnosed early $(\leq 24 \mathrm{~h})$ and those diagnosed later.

The general occurrence of esophageal perforations diagnosed during the study period translates into an es- timated incidence of 4.7/1,000,000 per year, considering the catchment area and the population of the two hospitals.

\section{Characteristics and Outcomes according to Cause of Perforation}

Clinical characteristics and outcomes according to cause of perforation are displayed in table 2 . The spontaneous perforation group comprised 6 patients with true Boerhaave syndrome [14], and 8 patients with spontaneous perforations related to various conditions, including malignant esophageal tumors (with or without a stent in place), infections or fistula, or suggested esophageal ischemia or inflammation. The cause of perforation was categorized as iatrogenic when the perforation occurred in relation to diagnostic (e.g. endoscopy or placement of a gastric tube; $n=7$ ) or therapeutic [e.g. surgical repair of a para-esophageal hernia $(n=6)$ or dilatation of a benign stricture $(n=8)$, related to cervical spine surgery $(n=2)$ or therapeutic procedures with a non-flexible scope $(\mathrm{n}=$ 2 )] procedures. Other causes of perforations included 
perforations related to food impaction $(\mathrm{n}=3)$, or encountered in multi-trauma patients $(\mathrm{n}=3)$, or after swallowing part of a denture or other foreign bodies $(n=2)$.

While ages were similar between groups, significant differences in the ASA score $(\mathrm{p}=0.004)$ indicate that general health was more compromised in patients with a spontaneous perforation. In addition, a distal localization of the perforation was significantly more common in the group with a spontaneous perforation $(\mathrm{p}=0.001)$. Time from symptom onset to diagnosis varied between groups, with a significantly longer delay in patients with spontaneous perforation $(\mathrm{p}=0.002)$.

We compared the clinical perforation score [5] between groups; in spite of rather similar median values, significant differences between groups were observed ( $p<$ 0.001 ) (table 2). However, no significant differences were encountered when distributions of severity categories of each perforation cause were compared between groups.

\section{Imaging and Work-Up}

Diagnostic imaging was done by esophagography with oral contrast in 20 patients (43\%), resulting in confirmation of a perforation in 13 (65\%) of these patients, a negative examination in 6 patients (30\%), and an indefinite conclusion for 1 patient. A computer tomography (CT) examination was performed in 38 (81\%) of the patients, with confirmation of a contrast leakage obtained in 23 (61\%). CT results additionally confirmed or supported a suspected clinical esophageal perforation in $33(87 \%)$ of these patients by showing indirect signs of esophageal injury - including a recognition of mediastinal air in $6(16 \%)$ and pneumoperitoneum in $4(11 \%)$ of the examined patients. A negative CT was reported in 2 patients (4\%), and 2 patients had an indefinite imaging. A CT was not included in the primary diagnostic work-up in $9(19 \%)$ of the patients. An upper endoscopy was done in 37 (79\%) of the patients, with a perforation confirmed in $20(54 \%)$ of these examinations. Uncertain or suspicious findings were reported in 6 patients (16\%), 9 patients (24\%) had other miscellaneous endoscopic findings, and a negative endoscopy was encountered in 2 (5\%) of the patients. Throughout the study period, the use of endoscopy remained virtually unchanged, but there was a trend of esophagography being replaced by CT imaging $(\mathrm{p}=0.021)$ for the primary diagnostic work-up of these patients.

\section{Management}

An operative approach was employed in $45 \%$ of the patients, with no differences observed with regard to cause of perforation (table 3). A non-operative approach was more common in patients with a cervical or thoracic localization of the perforation ( $p=0.045)$. Otherwise, no significant differences related to the therapeutic approach were seen with regard to demographics and clinical presentation. Surgery included a thoracotomy with drainage in 6 patients $(14 \%)$, thoracotomy with suture of the esophagus in $5(12 \%)$, esophageal resection in $3(7 \%)$, laparotomy + esophageal suture in 4 (9\%), and cervical incision and drainage in $2(5 \%)$. Additionally, various endoscopic (endoscopic stent, endoscopic transluminal drainages, placement of feeding tubes) or percutaneous interventions (i.e. ultrasound-guided drainage of effusions and/or abscesses) were performed, sometimes repeatedly, in 9 patients (20\%), who were not otherwise surgically treated. In 16 patients (36\%), no specific interventions or operations were applied.

The proportion of patients with severe or life-threatening complications (Clavien-Dindo grade III-V) was significantly higher in the surgically treated group. The surgically treated patients also experienced a significantly $(\mathrm{p}<$ $0.001)$ longer stay in the ICU, and a significantly $(\mathrm{p}=0.022)$ longer time on ventilation. However, hospitalization times and 30-day mortality were similar for both groups.

\section{Clinical Perforation Score}

When patients were categorized into three risk groups according to their clinical perforation score at presentation (as suggested by Abbas et al. [5]) no differences were observed with regard to demographics (table 4). However, when evaluating diagnostic delay versus clinical perforation score category, we observed that the proportion of patients with an early diagnosis $(<24 \mathrm{~h})$ was significantly higher $(\mathrm{p}=0.033)$ in the lower risk group $(87 \%)$ as compared to the middle (37\%) and higher (47\%) risk groups. This did not translate into significant differences regarding main outcomes, including ICU stay or 30-day mortality.

\section{General Outcomes}

The 30 -day mortality was $23.4 \%(11 / 44)$ and the total in-hospital mortality was $27.7 \%$ ( 13 deaths in total). Causes of death included sepsis and multi-organ failure $(n=9)$, chronic obstructive respiratory disease $(n=2)$, aspiration $(\mathrm{n}=1)$, and advanced malignant disease $(\mathrm{n}=1)$. The causes of death were mostly determined based on clinical evaluation; autopsy was performed in only 4 patients (31\%). In a number of patients whose clinical evaluation suggested death from multi-organ failure, significant comorbidity (including malignant disease, alcoholism, or obvious cardio-respiratory incapacity) should be recognized as important cofactor for the detrimental outcome. 
Table 3. Characteristics and outcomes after non-operative or operative treatment

\begin{tabular}{|c|c|c|c|}
\hline Variable & $\begin{array}{l}\text { Non-operative } \\
\mathrm{n}=26(55 \%)\end{array}$ & $\begin{array}{l}\text { Operative } \\
\mathrm{n}=21(45 \%)\end{array}$ & $\mathrm{p}$ value \\
\hline Gender, M:F & $13: 13$ & $13: 8$ & 0.425 \\
\hline Median age, years (range) & $63(15-88)$ & $62(22-87)$ & 0.732 \\
\hline \multicolumn{4}{|l|}{ ASA score } \\
\hline 1 & $3(12)$ & $3(14)$ & \multirow[t]{4}{*}{0.171} \\
\hline 2 & $14(54)$ & $5(24)$ & \\
\hline 3 & $8(31)$ & $10(48)$ & \\
\hline 4 & $1(3)$ & $3(14)$ & \\
\hline \multicolumn{4}{|l|}{ Localization of perforation } \\
\hline Cervical & $6(23)$ & $4(19)$ & \multirow[t]{3}{*}{0.045} \\
\hline Thoracic & $14(54)$ & $5(24)$ & \\
\hline Distal/GEJ & $6(26)$ & $12(57)$ & \\
\hline In-hospital perforation & $10(39)$ & $8(38)$ & 0.980 \\
\hline \multicolumn{4}{|l|}{ Perforation cause } \\
\hline Spontaneous & $8(31)$ & $6(29)$ & \multirow[t]{3}{*}{0.944} \\
\hline Iatrogenic & $14(54)$ & $11(52)$ & \\
\hline Other & $4(16)$ & $4(19)$ & \\
\hline Median time from perforation to diagnosis, $\mathrm{h}$ (range) & $27(0-200)$ & $21(0-178)$ & 0.514 \\
\hline \multicolumn{4}{|l|}{ Presentation } \\
\hline Early $<24 \mathrm{~h}$ & $13(50)$ & $11(52)$ & \multirow[t]{2}{*}{0.871} \\
\hline Late & $13(50)$ & $10(21)$ & \\
\hline \multicolumn{4}{|l|}{ Complication severity grades $\mathrm{I}-\mathrm{V}^{1}$} \\
\hline I minor & $2(8)$ & $1(5)$ & \multirow[t]{5}{*}{0.033} \\
\hline II pharmacologic treatment & $7(27)$ & $1(5)$ & \\
\hline III intervention & $11(61)$ & $7(33)$ & \\
\hline IV life-threatening & $1(4)$ & $5(24)$ & \\
\hline $\mathrm{V}$ death & $5(11)$ & $7(33)$ & \\
\hline Median ICU stay, days (range) & $0(0-41)$ & $6(0-38)$ & $<0.001$ \\
\hline Days on ventilation, median (range) & $0(0-15)$ & $1(0-16)$ & 0.022 \\
\hline Days of hospitalization, median (range) & $15(3-58)$ & $27(1-110)$ & 0.166 \\
\hline 30-day mortality & $6(23)$ & $5(24)$ & 0.953 \\
\hline
\end{tabular}

Values are numbers (\%), unless otherwise indicated. GEJ = Gastro-esophageal junction. ${ }^{1}$ According to Dindo et al. [20].

\section{Discussion}

Our estimated annual incidence of 4.7 esophageal perforations per population of 1,000,000 is largely in concert with previous reports from Iceland and Denmark [3, 4]. The demographics of our population are also comparable with those reported from other Nordic countries [3, 4, 13], Europe [10], and the USA [5]. The younger age of patients encountered in other parts of the world reflects a difference in etiologies of esophageal perforation. In India, perforations after dilatation of corrosive strictures constitutes the major etiology, and the average patient is at least 20 years younger than most patients encountered in the Western world [6].

The rather low proportion of patients diagnosed with a spontaneous perforation (i.e. true Boerhaave syndrome) in this study is in contrast to previously reported rates of between $30-37 \%[5,13]$. These variations may be partly explained by different case mixes, varied referral patterns, as well as a different understanding of the definition of a true Boerhaave syndrome; for example, in this study we did not consider a 'spontaneous' esophageal perforation caused by peri-esophageal malignancy to be a true Boerhaave syndrome.

We observed 3 multi-trauma patients with esophageal perforation after blunt injury. Although rarely encountered, and seldom consided in most series, trauma is a well-known cause of esophageal perforation [21].

About half of our patients experienced a diagnostic delay (at least $24 \mathrm{~h}$ from symptom onset), which is comparable with findings of a recent study on spontaneous perforations [22], as well as with those of other reports on 
Table 4. Characteristics and outcomes according to clinical perforation score ${ }^{1}$

\begin{tabular}{|c|c|c|c|c|}
\hline \multirow[t]{2}{*}{ Variable } & \multicolumn{3}{|c|}{ Clinical perforation score ${ }^{1}$} & \multirow[t]{2}{*}{$\mathrm{p}$ value } \\
\hline & $\begin{array}{l}\leq 2 \\
\mathrm{n}=9(18 \%)\end{array}$ & $\begin{array}{l}3-5 \\
n=19(41 \%)\end{array}$ & $\begin{array}{l}>5 \\
\mathrm{n}=19(41 \%)\end{array}$ & \\
\hline Gender, M:F & $6: 3$ & $9: 10$ & $11: 8$ & 0.605 \\
\hline Median age, years (range) & $63(31-87)$ & $63(15-89)$ & $62(28-82)$ & 0.171 \\
\hline \multicolumn{5}{|l|}{ ASA score } \\
\hline 1 & $1(12)$ & $3(16)$ & $2(10)$ & \multirow[t]{4}{*}{0.753} \\
\hline 2 & $4(44)$ & $9(47)$ & $6(32)$ & \\
\hline 3 & $4(44)$ & $6(32)$ & $8(42)$ & \\
\hline 4 & 0 & $1(5)$ & $3(16)$ & \\
\hline \multicolumn{5}{|l|}{ Perforation cause } \\
\hline Spontaneous & $1(11)$ & $5(26)$ & $8(42)$ & \multirow[t]{3}{*}{0.289} \\
\hline Iatrogenic & $7(78)$ & $9(48)$ & $9(47)$ & \\
\hline Other & $1(11)$ & $5(26)$ & $2(11)$ & \\
\hline \multicolumn{5}{|l|}{ Presentation } \\
\hline Early $\leq 24 \mathrm{~h}$ & $8(89)$ & $7(37)$ & $9(47)$ & \multirow[t]{2}{*}{0.033} \\
\hline Late & $1(11)$ & $12(63)$ & $10(53)$ & \\
\hline Median ICU stay, days (range) & $0(0-10)$ & $1(0-39)$ & $3(0-41)$ & 0.418 \\
\hline Days on ventilation, median (range) & $0(0-9)$ & $0(0-16)$ & $0(0-15)$ & 0.936 \\
\hline Days of hospitalization, median (range) & $22(0-36)$ & $14(3-110)$ & $28(1-53)$ & 0.575 \\
\hline \multicolumn{5}{|l|}{ Complication severity grades I-V $\mathrm{V}^{2}$} \\
\hline I minor & 0 & $2(11)$ & $1(5)$ & \multirow[t]{5}{*}{0.661} \\
\hline II pharmacological treatment & $3(33)$ & $4(21)$ & $1(5)$ & \\
\hline III intervention & $2(22)$ & $7(37)$ & $9(47)$ & \\
\hline IV life-threatening & $1(11)$ & $2(11)$ & $3(16)$ & \\
\hline $\mathrm{V}$ death & $3(33)$ & $4(21)$ & $5(26)$ & \\
\hline 30-day mortality & $4(44)$ & $3(16)$ & $4(21)$ & 0.235 \\
\hline
\end{tabular}

Values are numbers (\%), unless otherwise indicated. ${ }^{1}$ According to Abbas et al. [5]. ${ }^{2}$ According to Dindo et al. [20].

esophageal perforations of various causes [23, 24]. The reported proportions of patients with a diagnostic delay vary between $25-50 \%$ in many series. It has been suggested that the time interval from perforation until confirmed diagnosis is of great importance both for appropriate treatment decisions and for outcomes $[25,26]$; however, this importance has been questioned by others $[18,27]$. There is some uncertainty regarding the reliability of reported delays in studies that are mostly retrospective.

A clinical score may provide useful information for decision-making and prognostication; it could also help to classify and describe the severity patterns of various patient series, enabling more appropriate comparisons of results and outcomes when various treatment approaches are employed in different series. As recently suggested by Abbas et al. [5], for a perforation score to be clinically useful in the management of patients with esophageal perforations, it must be tested in multiple series for validation. To the best of our knowledge, the clinical score tested in the present study had not yet been evaluated or validated by others. While several clinical aspects and factors are obviously useful for appropriate evaluation of these patients, it is uncertain why the authors [5] included some variables into their score, and why different weights were attributed to some of the included variables. Furthermore, no statistical models or calculations seem to support the suggested score. In this particular context, such information would be of particular interest, because the current scientific evidence is mostly based on smaller retrospective studies.

In the evaluation of results and the reliability of scores based on retrospective studies, comparisons may be hampered by the fact that detailed clinical information on important aspects or variables may not be available for registration and further evaluation. In most hospitals, including larger referral centers, the rarity of esophageal perforations is evident. Moreover, the diverse patterns of patients' individual health condition and the clinical presentation of this emergency require a careful and thor- 
ough evaluation to ensure appropriate diagnostic workup and management $[10,17,28]$. The majority of patients with iatrogenic perforations are diagnosed immediately or early after the incident, and these patients are already mostly under hospital care. In this particular group of patients, a clinical perforation score is suggested to be very low or zero. A clinical perforation score would be more useful and attractive if additional guidance could be provided in the more complex cases that are frequently encountered in patients with various spontaneous perforations. As for now, it remains uncertain if this score may add any useful information with regard to clinical management and prognostication of patients with esophageal perforation. Nevertheless, application of well-defined criteria on various study populations may provide information, which may partly explain differences in demographics and clinical characteristics of various reports. Differences in case mix may partly explain the range in outcomes.

For evaluation and grading of complications, we used the Clavien-Dindo criteria [20]. These criteria are commonly used for characterization of postoperative complications, and are referred to in many recent publications. However, it remains uncertain if this classification is appropriate in this particular setting, with a heterogeneous study population managed by a variety of treatment modalities. Specifically, it may be difficult to clinically differentiate between a complication or consequence of the perforation, and a complication of the applied treatment. Nevertheless, serious complications requiring appropriate treatments were encountered in the majority of our patients, and the patterns and severity of complications are of relevance in describing the study population, and for comparisons with others.

Several decades ago, Cameron et al. [29] introduced a non-operative approach for select groups of esophageal perforation patients; this approach has received more attention during recent years. Patients included in the present study population have not been treated according to a specific common protocol. Management was mostly guided by interpretation of the current literature, and commonly supervised clinically by fellow surgeons with a particular interest to competence and responsibility for upper GI surgery. The indications for operative treatment were generally a short delay between perforation and diagnosis (less than $24 \mathrm{~h}$ ), judgment of the patient's comorbidity, and also to some extent the individual evaluation of the clinical setting. In addition, treatment decisions might also have been influenced by qualifications of the attending surgeon on call.
We did not observe any significant changes in case management at our hospitals during the study period, which may partly be explained by the limited time period of 11 years. Of interest, we observed that ultrasoundguided percutaneous drainages or endoscopic transluminal drainages [30] have been more commonly employed during recent years, both as a supplement to surgery, and sometimes instead of operative treatment. It has recently been suggested that a number of contemporary non-operative techniques, including clips [31], stents [32-34], and vacuum therapies $[35,36]$, be used both as primary treatment for the perforation and as secondary tools when complications occur. These techniques are regarded as feasible and promising; however, the overall clinical experience is limited, and most related publications are case series with very few patients. Further clinical evaluation is necessary to determine the precise role of these tools in the management of these often high-risk patients [19]. Our own results do not allow for firm detailed recommendations regarding the management of this group of patients. Nevertheless, some guidance would be useful in the clinical setting, and algorithms have been suggested. In that respect, we think that the concept outlined by Brinster et al. [37] would be of some relevance. However, based on a recent series from the UK published by Di Franco et al. [38], the treatment of patients with malignant esophageal perforations should receive particular attention. As emphasized by these authors, aggressive surgery in patients with malignant perforations is rarely beneficial, and a non-operative approach is recommended [38]. Although the general limitations of algorithms are well-known, we have tried to merge various considerations put forward by several authors and by Brinster et al. [37] and Di Franco et al. [38] in particular, when we developed an algorithm (fig. 1), which may be of some help in the clinical management of these patients.

The present study was based on consecutive patients referred from a geographically well-defined area with a continuously expanding population of around 900,000 people on average during the study period. Thus, it is a strength of this population-based study that, to the best of our knowledge, the patient series comprised all eligible patients with esophageal perforation in this area. The annual incidence of $4.7 / 1,000,000$, the demographics, and the outcomes were comparable with those recently reported from other Nordic countries $[3,4,13]$.

The rarity of this potentially life-threatening emergency is a limitation of this study. As with several previous studies $[5,7,8,11,39]$, our results were based on a 


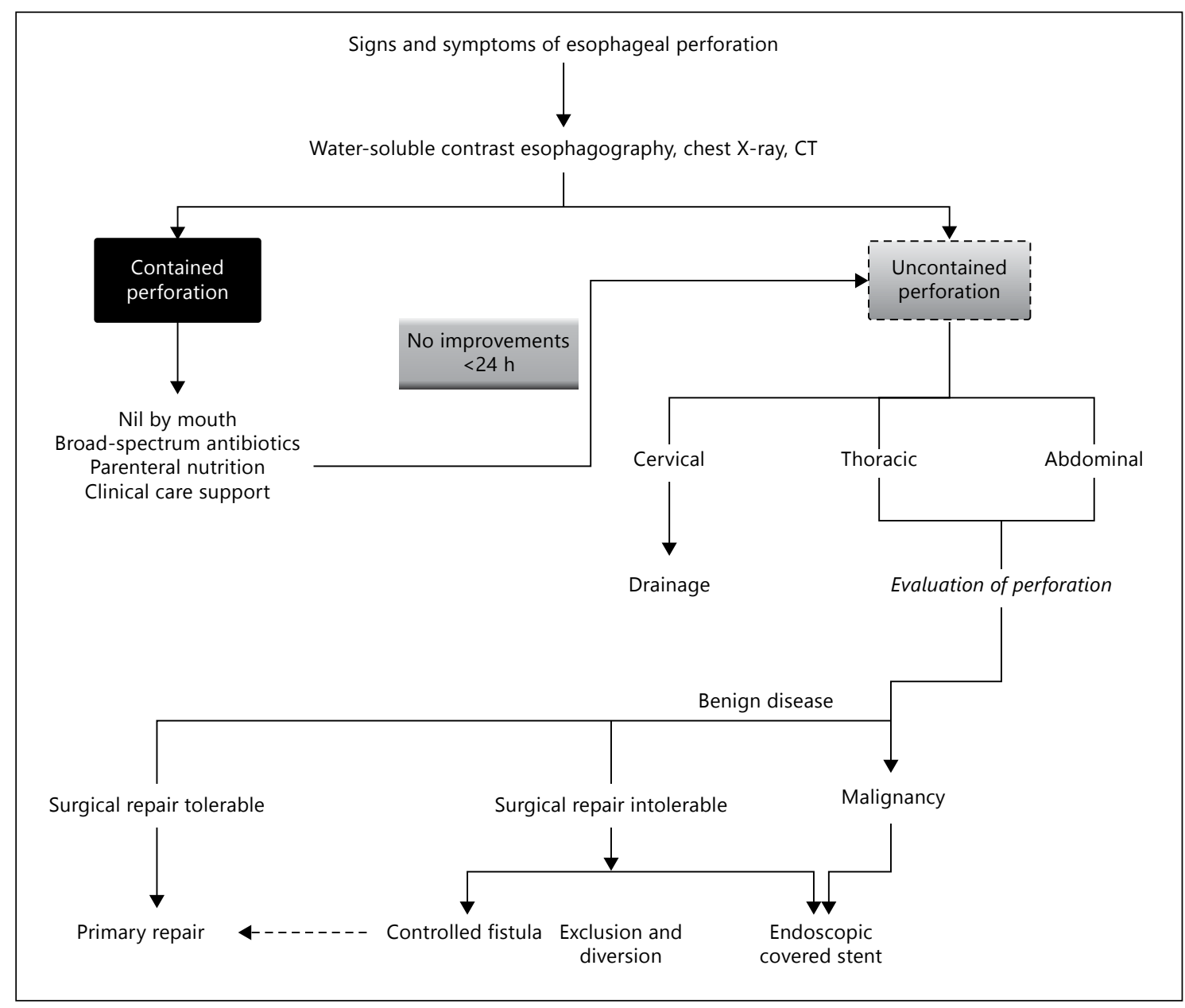

Fig. 1. Evaluation and treatment of esophageal perforation (adapted from $[37,38]$ ).

retrospective evaluation of available data. Morbidity and mortality following esophageal perforation are generally high, although varying between series. We observed a relatively high mortality of $23.6 \%$, and this was mainly related to diagnostic delay, comorbidity and patients with advanced cancers. However, comparing the present figures with previously reported data from other series remains a challenge. Different variables have been included in various studies, and the interpretation and implementation of definitions (e.g. diagnostic delay, leukocytosis, contained leak, respiratory compromise, hypotension, sepsis, and complication) likely differ among many reports [40]. Furthermore, mortality is reported differently, often with less concern about the possible discrepancies of reporting 30-day mortality and in-hospital mortality [5-7]. Consequently, comparisons of results are difficult. However, true prospective (multi- center) studies are hardly practicable in this context due to the very low patient recruitment over time, and a randomized controlled study would likely be underpowered due to logistic constraints involved in conducting such a study.

This study on 11 years of management of esophageal perforation cases reveals that, while the incidence remains almost the same, and the clinical management of this rare emergency is still a challenge, the diagnostic and therapeutic toolbox is expanding. Substantial morbidity and mortality remain of concern. Detrimental outcomes are likely related to the etiology of the perforation as well as the appropriateness of treatment. Our findings also indicate that general comorbidity and underlying malignant disease commonly encountered in these often fragile patients should be taken into consideration when results from various heterogeneous series are compared. 


\section{References}

1 Øvrum E, Birkeland S, Bugge-Asperheim B: [Perforation and rupture of esophagus. Diagnosis and treatment]. Tidsskrift for den Norske laegeforening: tidsskrift for praktisk medicin, ny raekke 1982;102:489-492.

-2 Skinner DB, Little AG, DeMeester TR: Management of esophageal perforation. Am J Surg 1980;139:760-764.

-3 Vidarsdottir H, Blondal S, Alfredsson H, Geirsson A, Gudbjartsson T: Oesophageal perforations in Iceland: a whole population study on incidence, aetiology and surgical outcome. Thorac Cardiovasc Surg 2010;58: 476-480.

4 Ryom P, Ravn JB, Penninga L, et al: Aetiology, treatment and mortality after oesophageal perforation in Denmark. Dan Med Bull 2011; 58:A4267.

5 Abbas G, Schuchert MJ, Pettiford BL, et al: Contemporaneous management of esophageal perforation. Surgery 2009;146:749-755; discussion 755-756.

-6 Amudhan A, Rajendran S, Raj VV, et al: Management of esophageal perforation: experience from a tertiary center in India. Dig Surg 2009;26:322-328

-7 Eroglu A, Turkyilmaz A, Aydin Y, Yekeler E, Karaoglanoglu N: Current management of esophageal perforation: 20 years experience. Dis Esophagus 2009;22:374-380.

-8 Onat S, Ulku R, Cigdem KM, Avci A, Ozcelik C: Factors affecting the outcome of surgically treated non-iatrogenic traumatic cervical esophageal perforation: 28 years experience at a single center. J Cardiothorac Surg 2010;5:46.

-9 Paul I, Badmanaban B, Graham AN: Perforation of the lower thoracic oesophagus following crush injury to the chest and abdomen. Eur J Cardiothorac Surg 2005;27:526-528.

10 Vallbohmer D, Holscher AH, Holscher M, et al: Options in the management of esophageal perforation: analysis over a 12-year period. Dis Esophagus 2010;23:185-190.

11 Gupta NM, Kaman L: Personal management of 57 consecutive patients with esophageal perforation. Am J Surg 2004;187:58-63.

-12 Bufkin BL, Miller JI Jr, Mansour KA: Esophageal perforation: emphasis on management. Ann Thorac Surg 1996;61:1447-1451; discussion 1451-1452.

13 Hermansson M, Johansson J, Gudbjartsson T, et al: Esophageal perforation in South of Sweden: results of surgical treatment in 125 consecutive patients. BMC Surg 2010;10:31.

14 Barrett NR: Spontaneous perforation of the oesophagus; review of the literature and report of three new cases. Thorax 1946;1:48-70.
15 Derbes VJ, Mitchell RE Jr: Hermann Boerhaave's Atrocis, nec descripti prius, morbi historia, the first translation of the classic case report of rupture of the esophagus, with annotations. Bull Med Libr Assoc 1955;43:217240.

16 Lawrence DR, OhriSK, Moxon RE, Townsend ER, Fountain SW: Primary esophageal repair for Boerhaave's syndrome. Ann Thorac Surg 1999;67:818-820.

17 Søreide JA, Viste A: Esophageal perforation: diagnostic work-up and clinical decisionmaking in the first 24 hours. Scand J Trauma Resusc Emerg Med 2011;19:66.

18 Kuppusamy MK, Hubka M, Felisky CD, et al: Evolving management strategies in esophageal perforation: surgeons using nonoperative techniques to improve outcomes. J Am Coll Surg 2011;213:164-171; discussion 171172.

19 Eisendrath P: Esophageal leaks: extending our toolbox? Endoscopy 2010;42:753-754.

20 Dindo D, Demartines N, Clavien PA: Classification of surgical complications: a new proposal with evaluation in a cohort of $6336 \mathrm{pa}-$ tients and results of a survey. Ann Surg 2004; 240:205-213.

21 Henderson E, Echave V, Lalancette M, Langlois G: Esophageal perforation in closed neck trauma. Canadian J Surg 2007;50:E5-E6.

22 Griffin SM, Lamb PJ, Shenfine J, Richardson DL, Karat D, Hayes N: Spontaneous rupture of the oesophagus. Br J Surg 2008;95:11151120 .

23 Keeling WB, Miller DL, Lam GT, et al: Low mortality after treatment for esophageal perforation: a single-center experience. Ann Thorac Surg 2010;90:1669-1673; discussion 1673.

24 Vogel SB, Rout WR, Martin TD, Abbitt PL: Esophageal perforation in adults: aggressive, conservative treatment lowers morbidity and mortality. Ann Surg 2005;241:1016-1021;discussion 1021-1023.

25 Sepesi B, Raymond DP, Peters JH: Esophageal perforation: surgical, endoscopic and medical management strategies. Curr Opin Gastroenterol 2010;26:379-383.

26 Shaker H, Elsayed H, Whittle I, Hussein S, Shackcloth M: The influence of the 'golden 24-h rule' on the prognosis of oesophageal perforation in the modern era. Eur J Cardiothorac Surg 2010;38:216-222.
27 Bhatia P, Fortin D, Inculet RI, Malthaner RA: Current concepts in the management of esophageal perforations: a twenty-seven year Canadian experience. Ann Thorac Surg 2011; 92:209-215.

-28 Amir AI, van Dullemen H, Plukker JT: Selective approach in the treatment of esophageal perforations. Scand J Gastroenterol 2004;39: 418-422.

29 Cameron JL, Kieffer RF, Hendrix TR, Mehigan DG, Baker RR: Selective nonoperative management of contained intrathoracic esophageal disruptions. Ann Thorac Surg 1979;27:404-408.

30 Infante M, Valente M, Andreani S, et al: Conservative management of esophageal leaks by transluminal endoscopic drainage of the mediastinum or pleural space. Surgery 1996;119: 46-50.

31 Pohl J, Borgulya M, Lorenz D, Ell C: Endoscopic closure of postoperative esophageal leaks with a novel over-the-scope clip system. Endoscopy 2010;42:757-759.

32 Salminen P, Gullichsen R, Laine S: Use of selfexpandable metal stents for the treatment of esophageal perforations and anastomotic leaks. Surg Endosc 2009;23:1526-1530.

33 Dai YY, Gretschel S, Dudeck O, Rau B, Schlag PM, Hunerbein M: Treatment of oesophageal anastomotic leaks by temporary stenting with self-expanding plastic stents. Br J Surg 2009; 96:887-891.

-34 Kiev J, Amendola M, Bouhaidar D, Sandhu BS, Zhao X, Maher J: A management algorithm for esophageal perforation. Am J Surg 2007;194:103-106.

35 Loske G, Schorsch T, Muller C: Endoscopic vacuum sponge therapy for esophageal defects. Surg Endosc 2010;24:2531-2535.

36 Ahrens M, Schulte T, Egberts J, et al: Drainage of esophageal leakage using endoscopic vacuum therapy: a prospective pilot study. Endoscopy 2010;42:693-698.

- 37 Brinster CJ, Singhal S, Lee L, Marshall MB, Kaiser LR, Kucharczuk JC: Evolving options in the management of esophageal perforation. Ann Thorac Surg 2004;77:1475-1483.

- 38 Di Franco F, Lamb PJ, Karat D, Hayes N, Griffin SM: Iatrogenic perforation of localized oesophageal cancer. Br J Surg 2008;95:837-839.

39 Griffiths EA, Yap N, Poulter J, Hendrickse MT, Khurshid M: Thirty-four cases of esophageal perforation: the experience of a district general hospital in the UK. Dis Esophagus 2009;22:616-625.

40 Dindo D, Clavien PA: What is a surgical complication? World J Surg 2008;32:939-941. 